\title{
Crystal structure of hydrated $\mathrm{LaSr}_{3} \mathrm{Fe}_{3} \mathrm{O}_{8}(\mathrm{OH})_{2} \cdot x \mathrm{H}_{2} \mathrm{O}$
}

\author{
Vegar Øygarden ${ }^{l}$, Helmer Fjellvåg ${ }^{l}$, Magnus H. Sørby ${ }^{2}$ and Anja O. Sjåstad ${ }^{l}$. \\ ${ }^{1}$ Department of Chemistry, Centre for Materials Science and Nanotechnology, University of \\ Oslo, P.O. Box 1033, N-0315 Oslo, Norway \\ ${ }^{2}$ Institute for Energy Technology, N-2007, Kjeller, Norway.
}




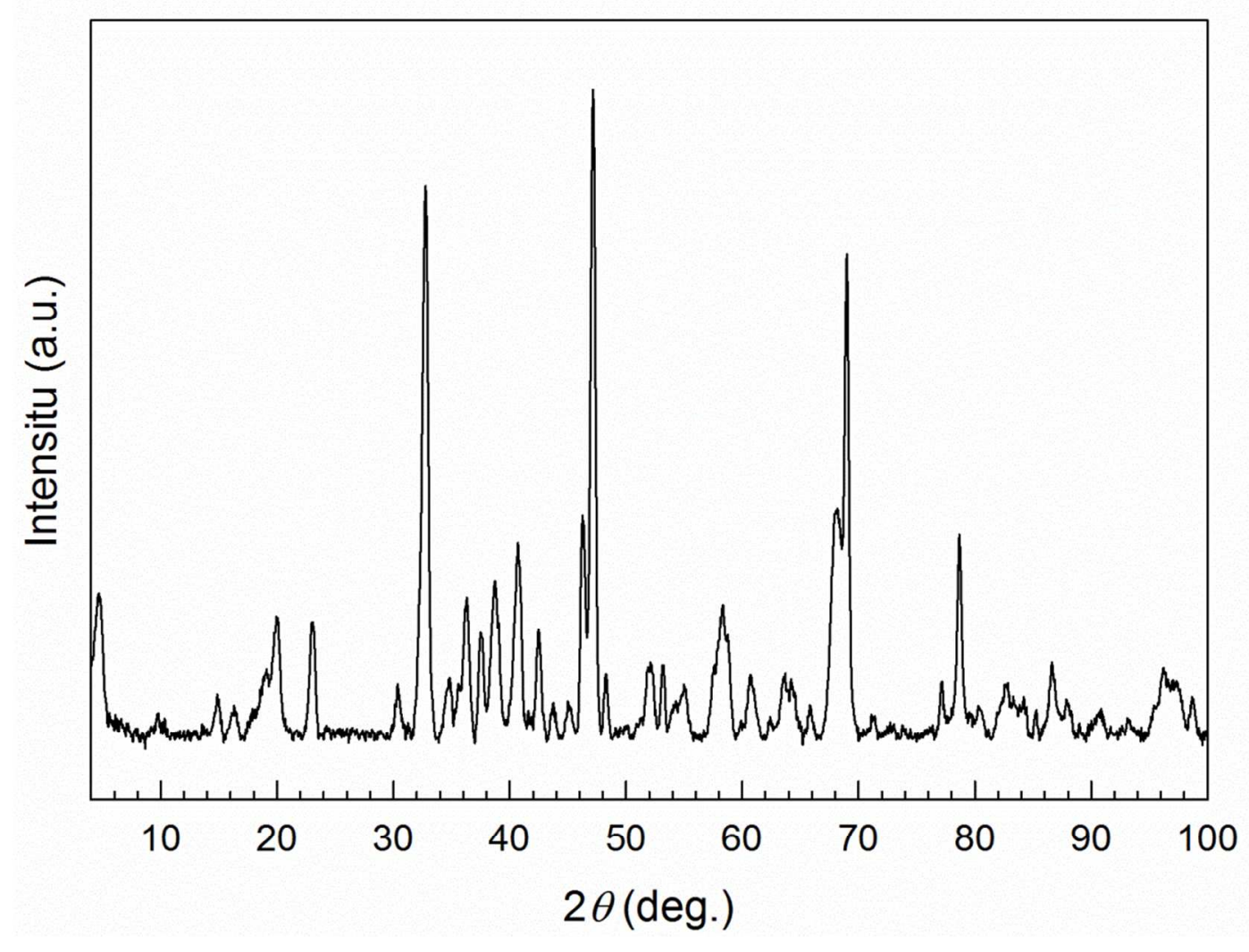

Figure S1. Neutron diffraction data for for $\mathrm{LaSr}_{3} \mathrm{Fe}_{3} \mathrm{O}_{8}(\mathrm{OD})_{2} \cdot 1.7 \mathrm{D}_{2} \mathrm{O}$ measured at $8 \mathrm{~K}$. $\lambda=$ $1.5538 \AA$. 


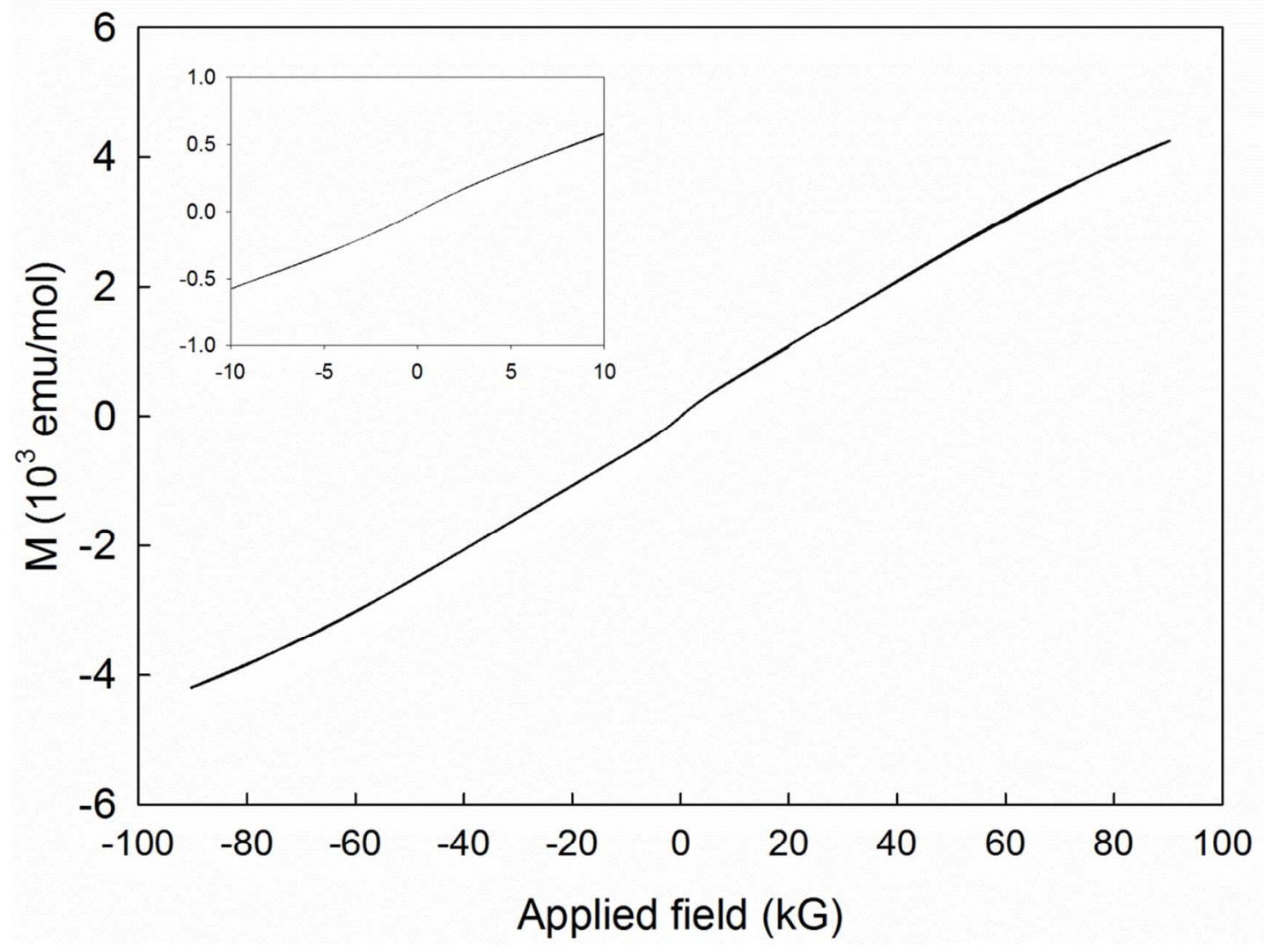

Figure S2. Magnetization hysteresis curve of $\mathrm{LaSr}_{3} \mathrm{Fe}_{3} \mathrm{O}_{8}(\mathrm{OH})_{2} \cdot 1.7 \mathrm{H}_{2} \mathrm{O}$. 
Table S1. Selected bond length calculated from Rietveld refinement of $\operatorname{LaSr}_{3} \mathrm{Fe}_{3} \mathrm{O}_{8}(\mathrm{OH})_{2}$ $\cdot 1.7 \mathrm{H}_{2} \mathrm{O}$ from combined SR-XRD and neutron diffraction data.

\begin{tabular}{|c|c|c|c|c|c|c|c|c|c|c|}
\hline & O1a & O1b & $\mathrm{O} 2$ & $\mathrm{O} 3 \mathrm{a}$ & $\mathrm{O} 3 \mathrm{~b}$ & $\mathrm{O} 4$ & O5 & H1/D1 & $\mathrm{H} 2 / \mathrm{D} 2$ & H3/D3 \\
\hline $\mathrm{La} / \mathrm{Sr} 1$ & $2.830(3)$ & $\begin{array}{l}2.832(4) \\
2.823(4)\end{array}$ & $2.835(15)$ & $2.745(13)$ & $\begin{array}{l}2.872(18) \\
2.897(18)\end{array}$ & - & - & - & - & - \\
\hline $\mathrm{La} / \mathrm{Sr} 2$ & - & - & - & $2.630(12)$ & $\begin{array}{l}2.482(18) \\
2.516(18)\end{array}$ & $\begin{array}{l}2.763(11) \\
2.818(12)\end{array}$ & $2.53(2)$ & - & - & - \\
\hline $\mathrm{Fe} 1$ & 1.9421 & 1.9457 & $1.954(15)$ & - & - & - & - & - & - & - \\
\hline $\mathrm{Fe} 2$ & - & - & $1.920(16)$ & $\begin{array}{l}1.90(2) \\
1.99(2)\end{array}$ & $1.972(3)$ & $2.369(18)$ & - & - & - & - \\
\hline $\mathrm{O} 4$ & - & - & - & - & - & - & - & $1.05(2)$ & - & - \\
\hline O5 & - & - & - & - & - & - & - & - & $1.50(2)$ & $1.53(2)$ \\
\hline
\end{tabular}

